\title{
Article \\ Study on Generating Machining Performance of Two-Dimensional Ultrasonic Vibration-Composited Electrolysis/Electro-Discharge Technology for MMCs
}

\author{
Jing $\mathrm{Li}^{1,2}$, Wanwan Chen ${ }^{1}$ and Yongwei $\mathrm{Zhu}^{1,2, *}$ \\ 1 School of Mechanical Engineering, Yangzhou University, Yangzhou 225127, China; \\ dx120180056@stu.yzu.edu.cn (J.L.); dx120190080@stu.yzu.edu.cn (W.C.) \\ 2 College of Hydraulic Science and Engineering, Yangzhou University, Yangzhou 225127, China \\ * Correspondence: ywzhu@yzu.edu.cn; Tel.: +86-0514-8797-8311
}

Citation: Li, J.; Chen, W.; Zhu, Y. Study on Generating Machining Performance of Two-Dimensional Ultrasonic Vibration-Composited Electrolysis/Electro-Discharge Technology for MMCs. Materials 2022, 15, 617. https://doi.org/10.3390/ ma15020617

Academic Editor: Khaled Giasin

Received: 5 December 2021

Accepted: 12 January 2022

Published: 14 January 2022

Publisher's Note: MDPI stays neutral with regard to jurisdictional claims in published maps and institutional affiliations.

Copyright: (C) 2022 by the authors. Licensee MDPI, Basel, Switzerland. This article is an open access article distributed under the terms and conditions of the Creative Commons Attribution (CC BY) license (https:// creativecommons.org/licenses/by/ $4.0 /)$.

\begin{abstract}
Ultrasonic vibration-composited electrolysis/electro-discharge machining technology (UE/DM) is effective for machining particulate-reinforced metal matrix composites (MMCs). However, the vibration of the tool or workpiece suitable for holes limits the application of UE/DM. To improve the generating machining efficiency and quality of flat and curved surfaces, in this study, we implemented two-dimensional ultrasonic vibration into UE/DM and constructed a novel method named two-dimensional ultrasonic vibration-composited electrolysis/electro-discharge machining (2UE/DM). The influence of vibration on the performance of 2UE/DM compared to other process technologies was studied, and an orthogonal experiment was designed to optimize the parameters. The results indicated that the materiel remove rate (MRR) mainly increased via voltage and tool vibration. The change current was responsible for the MRR in the process. Spindle speed and workpiece vibration were not dominant factors affecting the MRR; the spindle speed and tool and workpiece vibration, which reduced the height difference between a ridge and crater caused by abrasive grinding, were responsible for surface roughness (Ra) and form precision ( $\delta$ ). Additionally, the optimized parameters of $1000 \mathrm{rpm}, 3 \mathrm{~V}$, and $5 \mathrm{um}$ were conducted on MMCs of $40 \mathrm{SiCp} / \mathrm{Al}$ and achieved the maximum MRR and minimum $\mathrm{Ra}$ and $\delta$ of $0.76 \mathrm{~mm}^{3} / \mathrm{min}, 3.35 \mathrm{um}$, and 5.84\%, respectively. This study's findings provide valuable process parameters for improving machining efficiency and quality for MMCs of 2UE/DM.
\end{abstract}

Keywords: 2D ultrasonic vibration; electrolysis/discharge; MMCs; MRR; surface quality; form precision

\section{Introduction}

MMCs have outstanding advantages, but the performance of the two constituent materials differs. Therefore, conventional Grinding machining (GM) or special machining (such as electrolysis machining (ECM) and electro-discharge machining (EDM)) usually cannot achieve satisfactory machining efficiency and quality at the same time and tool wear is severe [1-3]. GM causes cracking, splitting, particle displacement, and serious tool wear $[4,5]$. Electric discharge machining (EDM) produces a recast layer by melting, enhances the shielding effect of particles, and reduces the machining efficiency [6]. In recent years, electrolysis/electro-discharge machining under a low current density has become the most promising technology for solving the problems experienced when machining composites. Electrolytic discharge machining (ECDM) is a technology that applies bubbles generated via electrolysis to form a gas film around electrodes and then induces discharge melting and chemical corrosion between a tool and a workpiece [7]. The nonconductive material in ECDM is mainly removed by the discharge between the gas film and workpiece, with chemical etching as the auxiliary method [8]. Although electrolytic/electro-discharge machining (E/DM) uses electrolysis and discharge phenomena, it is different from ECDM [9]. $\mathrm{E} / \mathrm{DM}$ combines the characteristics and advantages of ECM to remove metal material; EDM 
between a tool and workpiece and ECDM between a gas film and workpiece remove nonconductive materials as auxiliary methods. High-temperature melting and heat-accelerated chemical etching are applied on composite materials, and electrolytic dissolution of pits and protrusions is applied to reduce surface roughness. Liu [10] used GE/DM to machine MMCs and found that the removal mechanism is similar to that of ECDM and grinding, compounded to eliminate the recast layer and reduce the surface roughness by a diamond, abrasive, particles-coated tool. Kanagaraja [11] found that when the mass fraction of reinforced particles was higher, the cutting force needed to shear or break ceramic particles was greater. When the rotational speed of the tool electrode was increased, it had positive effects on machining performance.

The preceding analysis shows that the removal rate and machining precision of MMCs need to be enhanced. Many researchers have reported that a high vibration frequency or high vibration amplitude enhances electrolytic machining performance characteristics [1-13]. Anasane [14] and Ghoshal [15] reported that increasing tool vibration amplitude improves the performance characteristics and gap environment of ECM. Pawariya [16] used ultrasonic vibration of tool electrode of ECDM to investigate and enhance deep microholes in difficultto-machine metal materials. Wang [17] reported that tool vibration improves machining the efficiency, surface quality, and gap environment of ECM.

The abovementioned machining methods are mostly suitable for the microhole machining of metal, conductive materials. For nonconductive materials, ultrasonic vibrationcomposited electro-discharge machining is a suitable choice [18]. Razfar [19] and Elhami [20] introduced vibration to a tool to machine glass microholes and found that ultrasonic vibration increased the frequency and probability of discharges and improved the material removal rate and surface quality [21]. Schubert [22] found the processing speed can be increased by $40 \%$ and the aspect ratio of metal micromoles can reach 40 .

The above ultrasonic vibration-composited electro-discharge and electrolytic machining have outstanding advantages in applications with difficult-to-machine materials, such as enhancing machining efficiency and precision, intensifying the renewal of electrolyte, or reducing tool wear [23]. For MMCs that are difficult to machine using conventional or single unconventional processes, ultrasonic vibration is effective for machining reinforced matrices with higher hardness. However, thus far, there is no report on the generating machining of flat or curved surfaces using 2UE/DM.

Combining the advantages of the high surface quality produced by ultrasonic vibration of EC/DM and the high efficiency by grinding on MMCs, we constructed a method called two-dimensional ultrasonic vibration-composited electrolysis/electro-discharge (2UE/DM) that functions under low current density and low voltage to improve the machining efficiency and quality of MMCs. During the processing, the ultrasonic vibration direction of the tool and workpiece are axial ( $\mathrm{Z}$ direction) and tangential ( $\mathrm{X}$ direction), respectively. A schematic diagram of side-generating machining on a surface by $2 \mathrm{UE} / \mathrm{DM}$ is shown in Figure 1. In this study, we analyzed the material removal mechanism of 2UE/DM using comparative experiments on $\mathrm{SiCp} / \mathrm{Al}$ with different processes, and examined the material remove rate (MRR), surface roughness $(\mathrm{Ra})$, and form precision $(\delta)$ through experiments with different process parameters. 


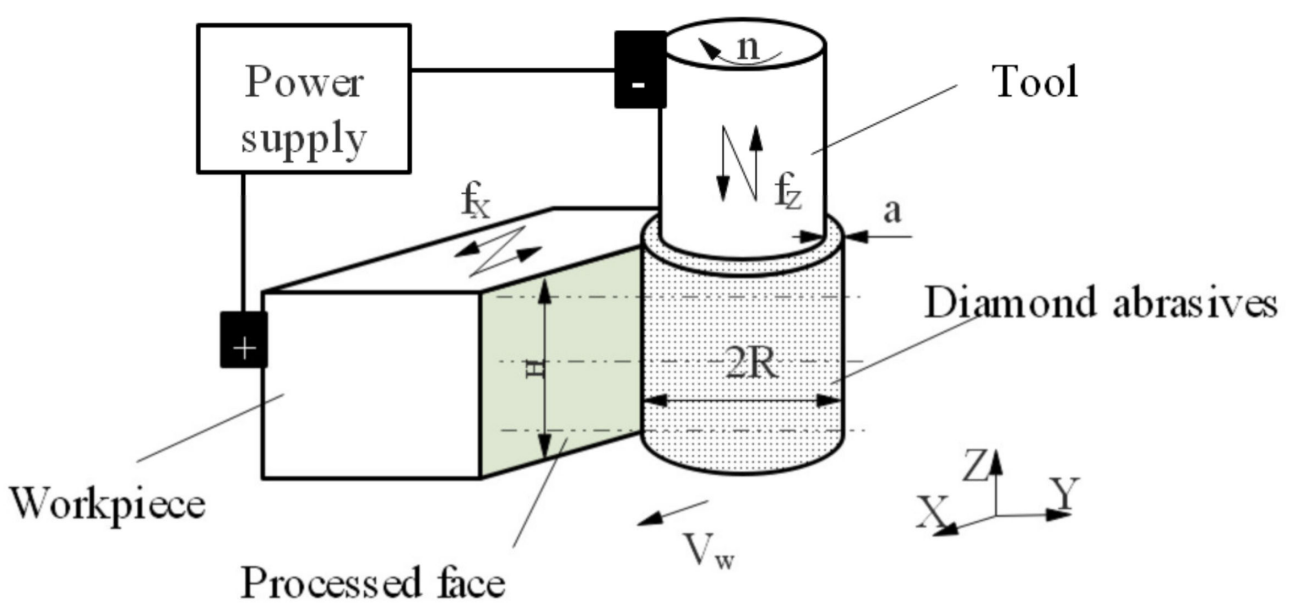

Figure 1. Schematic diagram of side-generating machining of 2UE/DM.

\section{UE/DM Machining Mechanism}

The proposed 2UE/DM is a technology combining two-dimensional ultrasonic vibrationassisted grinding machining (2UM), electrolysis machining (ECM), and discharge machining (DM). The gas and fluid in the machining gap are uniform and consistent under the effect of two-dimensional ultrasonic vibration, and the change in electrolyte conductivity by concentration difference, heat, and gas can be ignored. A conductive tool coated with diamonds was connected to the anode of the power source, whereas the workpiece was connected to the cathode of the power source; the gap between the electrodes was filled with passive electrolyte with low conductivity. The applied voltage was below $10 \mathrm{~V}$ and the current density was about $5-15 \mathrm{~A} / \mathrm{cm}^{2}$. The tool rotated, fed along the $\mathrm{X}$ direction, and vibrated axially simultaneously (with an amplitude of $\mathrm{A}_{Z}$ and a frequency of $\mathrm{f}_{\mathrm{Z}}$ ). The workpiece vibrated tangentially along the tool feed direction (with an amplitude of $A_{X}$ and a vibration frequency of $f_{X}$ ). The surface material of the workpiece was removed by a different removal mechanism with diffident displacements of ultrasonic vibration of the workpiece, as shown in Figure 2. In the machining process, the electrolytic dissolution rate was mainly affected by $A_{x}$ and the initial machining gap of $\mathrm{G}\left(t_{0}\right)$. The axial vibration and rotational movement of the tool had a slight effect on the machining gap. During one feed cycle of the workpiece, the machining gap $G(t)$ mainly varied periodically with the vibration of the workpiece, which can be expressed by Equation (1).

$$
\mathrm{G}(t)=\mathrm{G}\left(t_{0}\right)+\mathrm{AX}_{X} \sin \left(2 \pi \mathrm{f}_{\mathrm{X}} t\right)
$$

According to Faraday's law of electrolysis, the current density i mainly depends on the applied voltage drop $U_{R}$ and the machining gap $G(t), i \sim \frac{U_{R}}{G(t)}$. The vibration of the workpiece leads to the largest machining gap at $t_{1}$; additionally, the current density between the electrodes is lower, which avoids a short circuit or blockage occurring. The machined products and heat are ejected via pumping and renewing the electrolyte; this improves and stabilizes the machining environment [24]. The vibration of the workpiece leads to the smallest machining gap at $t_{3}$, when the electrolytic dissolution rate of the metal matrix reaches a maximum. Additionally, abrasive particles grind the workpiece and remove material; this achieves higher MRR and localized machining ability under low voltage of ECM. 


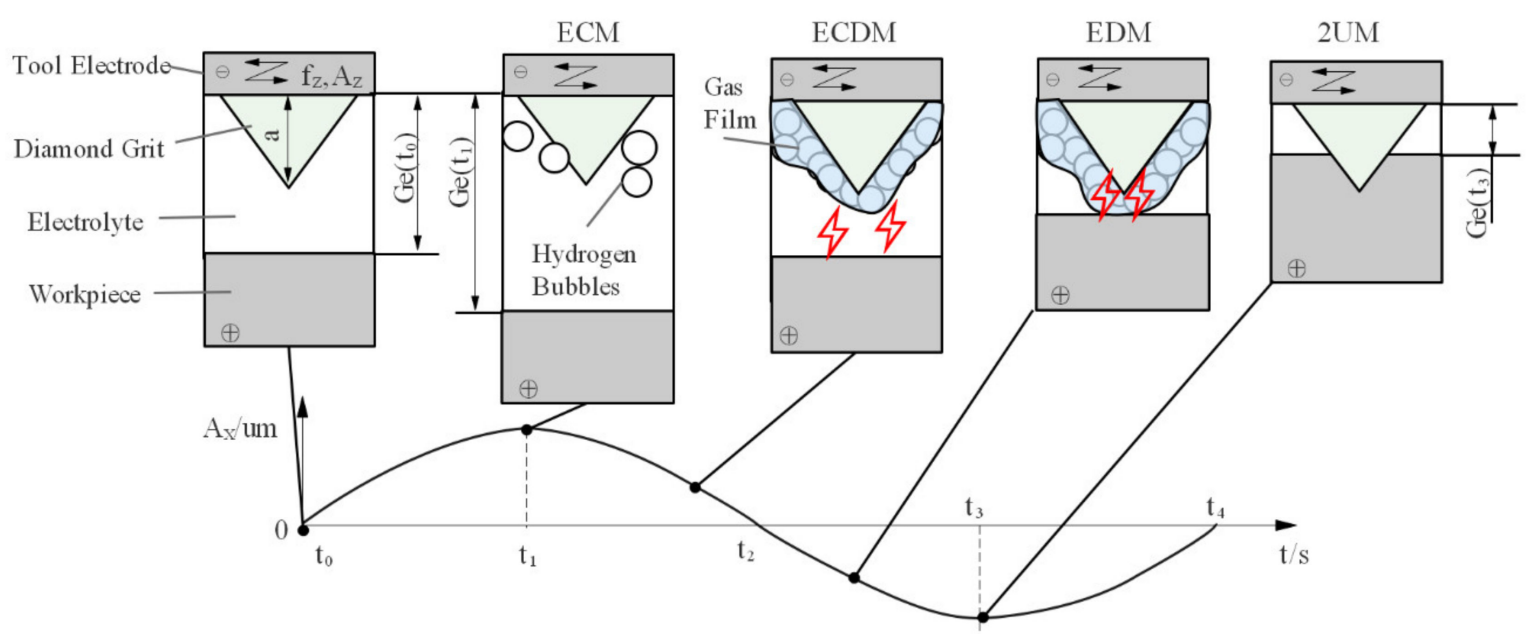

Figure 2. Schematic diagram of the 2UE/DM mechanism.

The DM means two types of machining: ECDM and EDM. The bubbles generated from the two electrodes accumulate on the surface of the tool under the action of buoyancy and surface tension; then, a gas film forms [25]. As the vibration of a workpiece increases, the machining gap $\mathrm{G}(t)$ becomes larger than the thickness of the gas film (the thickness of the gas film is generally $0.1-0.2 \mathrm{~mm}$ [24]); thus, the gas film isolates the tool and electrolyte, and ECDM occurs between the workpiece and electrolyte. If $\mathrm{G}(t)$ is less than the thickness of the gas film, the gas film insulates the electrodes. When the gap between the electrodes is 10-20 $\mu \mathrm{m}$ lower than the discharge gap, EDM occurs between the tool and workpiece, as shown in Figure 2. Although a static electrolyte is conducive to the formation of a more stable insulating gas film, an electrolyte or tool with compounded ultrasonic vibration is more conducive to the formation of a gas film and to the reduction in the thickness of the gas film; therefore, electro-discharge machining is possible under lower voltage [13]. The initial state between the electrodes is restored after electro-discharge machining and deionization. The distance between electrodes when the vibration of a workpiece is varied allows the electric field between the electrodes to still reach the discharge conditions and increases the probability and frequency of discharge, effectively removing passivation bumps in electrolysis to enhance the MRR.

The abrasive particles on the tool surface grinding machines in the ellipse trajectory of $2 \mathrm{UM}$ are similar to those of tangential microgrinding machining on the surface of the workpiece. In each microgrinding process, abrasive particles exhibit three types of machining. (1) The tangential ultrasonic impact on a workpiece causes abrasive particles to periodically hammer the surface of the workpiece, thereby obtaining smaller debris and varying the cutting depth of each microgrinding process. (2) In the microgrinding process, the abrasive particles are similar to the microgrinding blade and abrade the workpiece to produce tiny debris. The axial vibration of the tool extends the cutting arc length of the abrasive particles, enhances the removal ratio in the ductile zones of reinforced particulates, and widens the width of the grooves scraped by abrasive particles. (3) Under the joint action of $2 \mathrm{D}$ vibration and rotary grinding, rolling- and milling-like grinding are performed on the surface of the workpiece with wider coverage; this reduces protrusions after grinding and electrolytically insoluble points and strengthens the fractures and bulges of reinforced particles [10]. Hammering and abrasion of reinforced particulates is the major material removal form in $2 \mathrm{UM}$, whereas the rolling action varies the surface morphology and improves the surface quality [26]. 


\section{Experimental Setup}

Figure $3 a$ shows a schematic diagram of the 2UE/DM experimental device. Figure $3 b$ shows the in-house-built experimental equipment. The equipment was an ordinary grinder that included a Z-direction ultrasonic vibration head modified from a BT30 configured with a slip ring. During machining, the current was transmitted to the tool through a slip ring insulated from the machine tool and Z-direction ultrasonic generator. The workpiece was clamped on an elastic support frame that could slide in the $X$ direction, and the vibration was transmitted to the workpiece through an X-direction ultrasonic generator. The vibration frequencies of the tool and workpiece were 18.33 and $19.46 \mathrm{kHz}$, respectively.
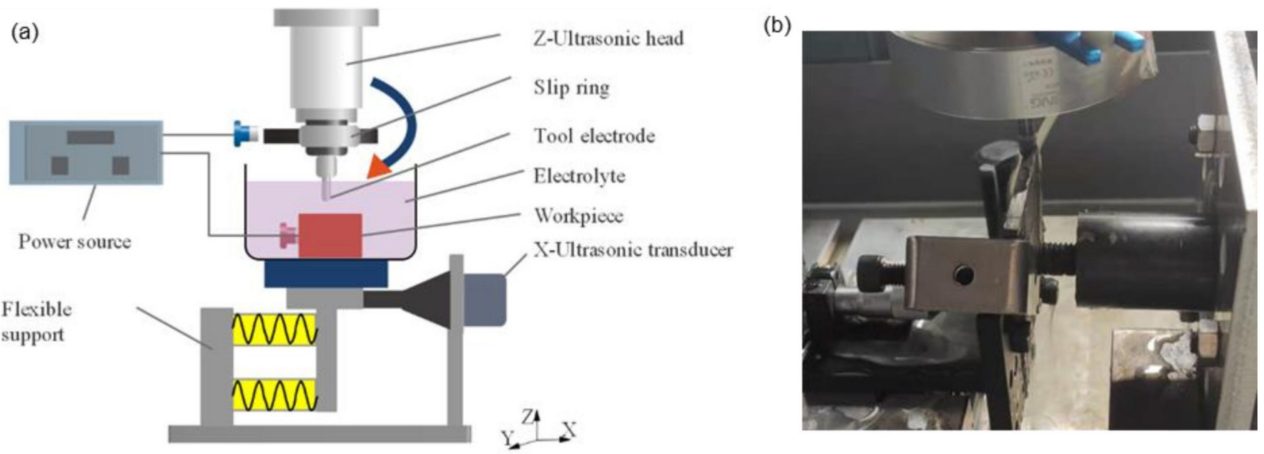

Figure 3. (a) Schematic diagram of the experimental setup and (b) the actual in-house-built equipment.

The workpiece was particulate-reinforced aluminum alloy 6061 with 40 vol.\% SiC reinforcement (40 $\mathrm{SiCp} / \mathrm{Al})$, as described in Table 1 . The tool material was WC with a diameter of $6 \mathrm{~mm}$ coated with diamond abrasive particles (100\#). The electrolyte was a 0.5 wt. \% $\mathrm{NaCO}_{3}$ solution pumped into the machining area through a nozzle during machining. The initial work piece was $50 \times 50 \times 5 \mathrm{~mm}$, and the machining surface was $50 \times 5 \mathrm{~mm}$ ground and cleaned before machining.

Table 1. Machining properties of $40 \mathrm{SiCp} / \mathrm{Al}$.

\begin{tabular}{ccccc}
\hline Material & APS $(\mu \mathrm{m})$ & Density $\left(\mathrm{g} / \mathrm{cm}^{3}\right)$ & $\begin{array}{c}\text { Yield Strength } \\
(\mathrm{MPa})\end{array}$ & $\begin{array}{c}\text { Modulus of } \\
\text { Elasticity (GPa) }\end{array}$ \\
\hline 6061Al 40vol.\% & 10 & 2.9 & 210 & 163 \\
\hline
\end{tabular}

To compare the forming quality and machining efficiency of 2UE/DM to other processes and to study the specific effects of 2D ultrasonic vibration, comparative tests were designed for clarifying the mechanisms: general grinding machining (GM), without vibration (GE/DM), Z vibration (ZUE/DM), X vibration (XUE/DM), and 2UE/DM, as shown in Table 2. From the four sets of signal factors tests, the effects of different process parameters on the MRR, surface quality, and edge precision of 2UE/DM were analyzed. A comparison of the parameters is shown in Table 3, and other parameters are shown in Table 2.

The power of the ultrasonic generator could be adjusted to vary the amplitudes of the workpiece and tool, and a laser microdisplacement sensor was used to measure the amplitude before the machining test. The machining time of each test was $3 \mathrm{~min}$. A balance that had a precision of $0.1 \mathrm{~g}$ was used to measure the removed mass and to calculate the MRR. Each test was performed three times, and the average value and standard deviation were calculated. The surface roughness of the machined surface was measured to evaluate the surface quality. A stereo-measuring microscope was used to observe the micropattern, and a Countour GT-K 3D optical profiler was used to measure and image the Ra and 3D appearance of the workpiece. The form precision [27] can be evaluated by the ratio of the cross-sectional area $S_{b}$ of the notch in the surface actually machined to the theoretical 
cross-sectional area $S_{c}$, as shown in Figure 4. L denotes the measured length, and H denotes the depth of the largest notch. Then, the form precision $\delta$ can be expressed by:

$$
\delta=\frac{\mathrm{S}_{\mathrm{b}}}{\mathrm{S}_{\mathrm{c}}}=\frac{\mathrm{S}_{\mathrm{b}}}{\mathrm{LH}}
$$

Table 2. Machining conditions for the mechanism.

\begin{tabular}{|c|c|c|c|c|c|}
\hline Category & GM & GE/DM & XUE/DM & ZUE/DM & 2UE/DM \\
\hline Static pressure & & & $5 \mathrm{~N}$ & & \\
\hline Electrolyte & & & 0.5 wt. $\% \mathrm{NaNO}_{3}$ & & \\
\hline Spindle speed (rpm) & & & 3000 & & \\
\hline Feed speed $(\mathrm{mm} / \mathrm{min})$ & & & 12 & & \\
\hline Machining depth (mm) & & & 0.01 & & \\
\hline Applied voltage (V) & 0 & 4 & 4 & 4 & 4 \\
\hline$X$ amplitude $(\mu \mathrm{m})$ & 0 & 0 & 4 & 0 & 4 \\
\hline $\mathrm{Z}$ amplitude $(\mu \mathrm{m})$ & 0 & 0 & 0 & 4 & 4 \\
\hline
\end{tabular}

Table 3. Machining parameters for 2UE/DM.

\begin{tabular}{ccccc}
\hline Group & Spindle Speed: $\mathbf{n}(\mathbf{r p m})$ & Applied Voltage: $\mathbf{~ ( V )}$ & $\mathbf{X}$ Amplitude: $\mathbf{A}_{\mathbf{X}}(\boldsymbol{\mu m})$ & Z-Amplitude: $\mathbf{A}_{\mathbf{Z}}(\boldsymbol{\mu m})$ \\
\hline 1 & $1000,2000,3000,5000$ & 4 & 4 & 4 \\
\hline 2 & 3000 & $3,4,5,6$ & 4 & 4 \\
\hline 3 & 3000 & 4 & $2,3,4,5$ & 4 \\
\hline 4 & 3000 & 4 & 4 & $2,3,4,5$ \\
\hline
\end{tabular}

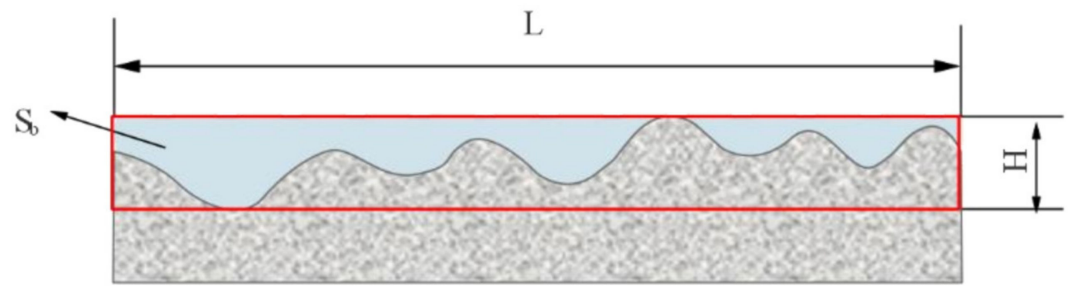

Figure 4. Method for calculating form precision.

\section{Comparative Analysis of Different Machining Mechanisms}

Figure 5 shows the waveforms of different machining currents. The gap between the tool and workpiece does not change theoretically in GE/DM and ZUE/DM, while the electrolysis current $(\mathrm{CH} 2$ : $\mathrm{I}=i \mathrm{~S}$, where $\mathrm{S}$ is the machining area) of ZUE/DM is almost the same without an ultrasonic wave, shown by the electrolytic/electro-discharge current (CH1) in Figure 5a,b. However, the electrolyte in the interelectrode gap cannot be renewed fast enough, the current stability of GE/DM is less than that of ZUE/DM, and discharges are rare in both; this is consistent with the analysis of the machining mechanism. In Figure $5 c$,d, the gap $G(t)=G\left(t_{0}\right)+A_{X} \sin \left(2 \pi f_{X} t\right)$ changes periodically with the vibration of the workpiece. The electrolysis current of 2UE/DM and ZUE/DM varied with the periodic vibration amplitude, a sudden increase due to EDM or ECDM occurred in the gap, and the frequency of discharges in 2UE/DM was significantly higher than that in ZUE/DM. This finding shows that two-dimensional ultrasonic vibration helps to increase the probability and frequency of discharge. It also avoids discharge at the same point and prevents the occurrences of short-circuit, arcing, and other phenomena. Electrolysis is an important method of removing material, and electro-discharge is more conducive to removing hard-to-dissolve and the reinforced fractured bumps of ceramic-based particles; they enhance the efficiency and stability of electrolytic machining. 


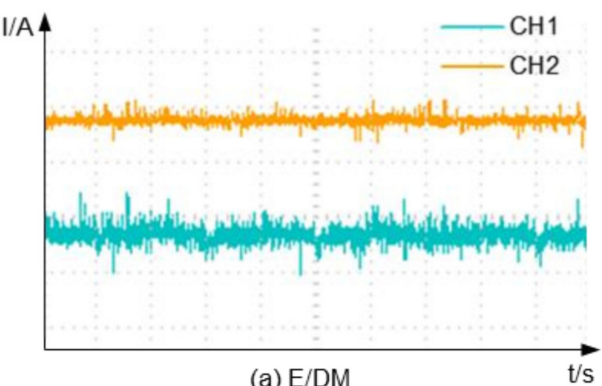

(a) $E / D M$

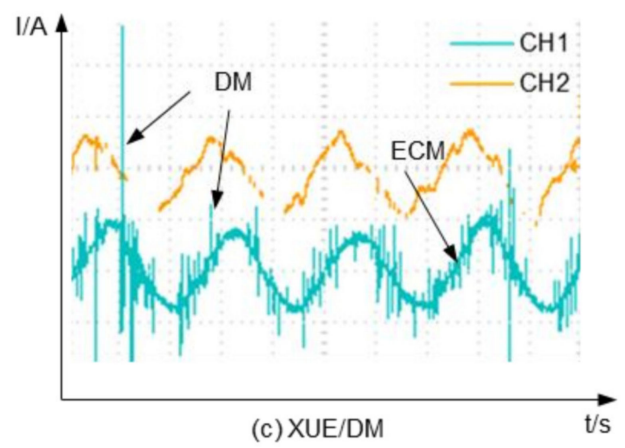

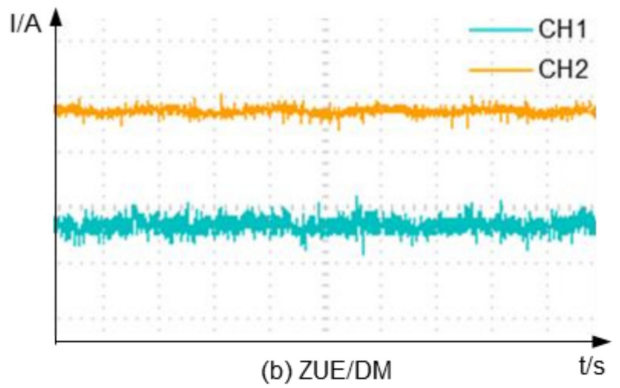

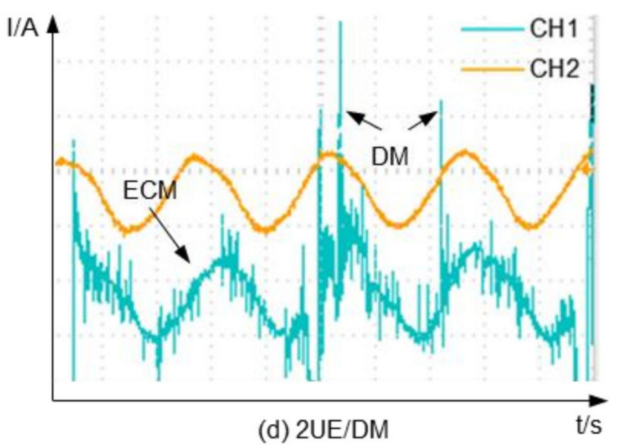

Figure 5. Comparison of current signals: (a) GE/DM; (b) ZUE/DM; (c) XUE/DM; (d) 2UE/DM.

Figure 6 shows the MRR data based on the experimental results of five machining processes. The varying machining gap helped to pump and renew the working fluid and discharge the machined products. The MRR of XUE/DM was slightly higher than that of ZUE/DM. Under the composited effect of 2D ultrasonic vibrations, the varied gap improved the machining efficiency. The MRR of 2UE/DM was higher by $18.9 \%, 13.1 \%$, $7.8 \%$, and $9.5 \%$ than that of GM, GE/DM, XUE/DM, and ZUE/DM, respectively. When there was no vibration, the uncycled electrolyte deteriorated the environment of machining gap gathered a large amount of material removal products and bubbles and reduced the material removal volume of E/DM. The abrasive particles not only scraped and activated the surface of the workpiece, but they also had a deeper grinding depth than that of GM, GE/DM, and ZUE/DM because of the X-direction vibration. This indicated that impact force in larger ultrasonic amplitude acted on the depth of wear debris, so it had a greater probability of the ceramic particles to be scraped or pulled out along the $\mathrm{X}$ direction, thereby significantly enhancing the machining efficiency.

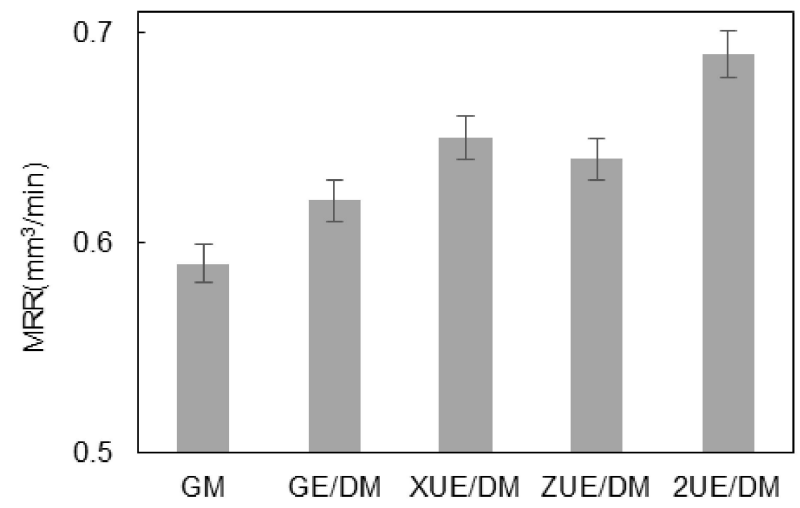

Figure 6. Comparison of machining efficiencies. 
Different motion trajectories of the abrasive particles with two-dimensional ultrasonic vibration simultaneously improved the surface quality of grinding and electrolysis/electrodischarge machining on the surface of the workpiece. The surface roughness and threedimensional morphologies are shown in Figures 7 and 8, respectively. As seen from the morphology formed by GM, there were obvious shapes of ridges and craters; these were cutting marks made by the abrasive particles. The maximum height difference between the ridges and craters was relatively large (about $155 \mu \mathrm{m}$ ). Pits and fracture marks of ceramic particles were visible at the material interfaces, showing a poorer surface quality; additionally, Ra was as high as $11 \mu \mathrm{m}$. In Figure 8b, the craters formed by GE/DM abrasive particles were shallower than those formed by GM with a depth of $147 \mu \mathrm{m}$; Ra decreased to about $6 \mu \mathrm{m}$ due to the electrolytic machining reducing the maximum height difference. The morphology formed by ZE/DM is shown in Figure 8c. The axial vibration increased the proportion of the plastic area, and only a small amount of debris breakage occurred when the surface was ground. The mechanism can basically be regarded as plastic shearing removing the ceramic particles. When the metal matrix dissolved, the squeezed zone and the marks of plastic grinding were removed, including the crater zone, while some particles were exposed. The ridge zone showed a small amount of residual fracture under the action of electrolysis and vibration. The maximum height difference decreased to $130 \mu \mathrm{m}$, and the ridge-crater morphology was not as obvious as in GE/DM and GM. This indicated the increased smoothness of the machined surface, with Ra being 20\% lower than for GE/DM. Figure $8 \mathrm{~d}$ shows that the cutting depth of abrasive diamond particles in XUE/DM was deeper than GM; only a few brittle fractures were observed on the surface. Although the impact force of $A_{X}$ increased the multilevel microcracks on ceramic particles, the exposed broken particles by ECM were pulled up and removed plastically. The repeatedly rolled area on the grinding surface increased, while the residual height decreased significantly along the tangential direction, and the surface height difference was only about $139 \mu \mathrm{m}$. Figure 8e shows that the surface formed by 2UE/DM was mainly composed of a grinding zone of plastic particles and an electrolysis zone of a metal matrix. Electrolysis of the metal matrix led to a reduction in the regular traces of machined plastic craters and ridges under the action of two-dimensional vibration. The proportion of the plastic machining zone was relatively large, and a single particle broke and fell off because of the dissolution of the metal matrix. The variations in morphology showed that the two-dimensional vibration and the rapid dissolution of the metal matrix accelerated the removal of composites. This was associated with the axial vibration plastic domain grinding of tools and the feed direction of vibration rolling. Thus, the maximum height difference between ridges and craters decreased by $125 \mu \mathrm{m}$, and Ra decreased to $3.4 \mu \mathrm{m}$. The surface of the workpiece was more flat and uniform, and the surface quality was significantly improved.

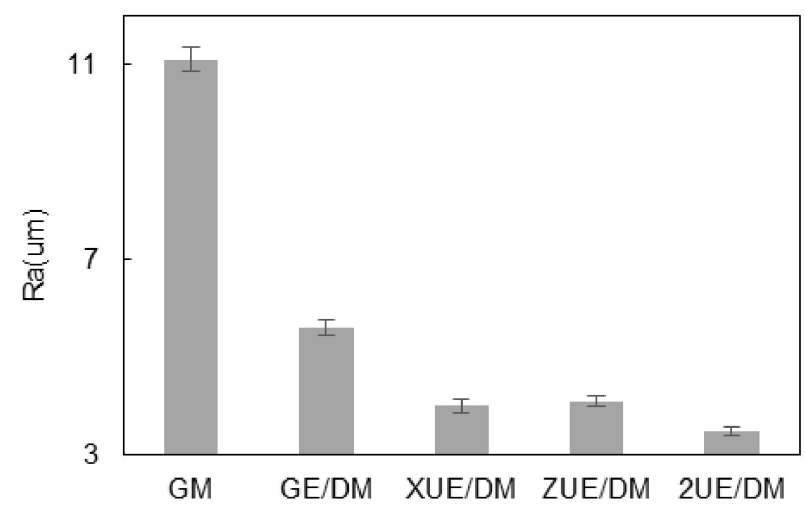

Figure 7. Comparison of surface roughness. 

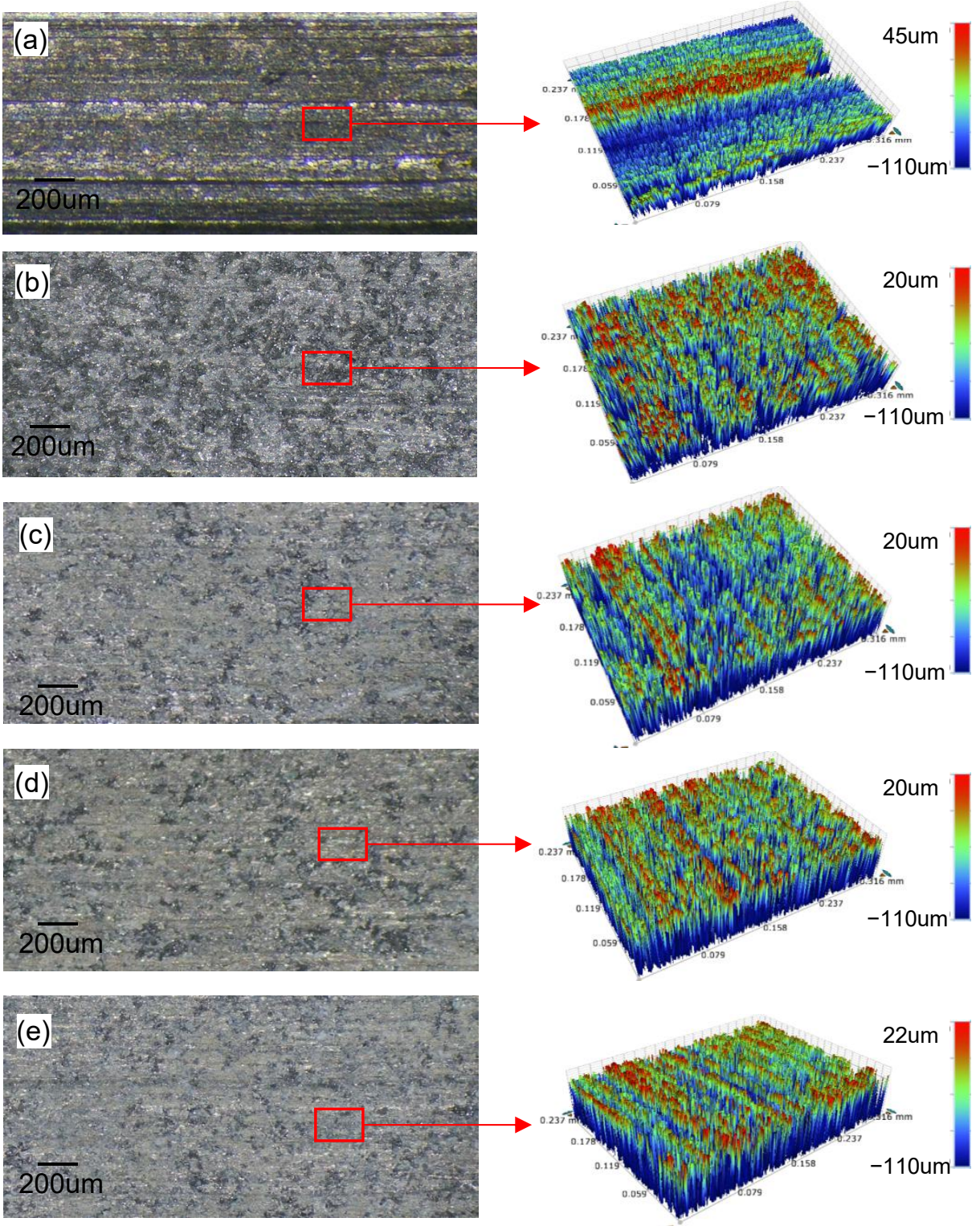

Figure 8. Comparison of machined surface and topographies: (a) GM; (b) GE/DM; (c) ZUE/DM; (d) XUE/DM; (e) 2UE/DM.

As observed from the microtopography of the machined edge (Figure 9), the form precision differed by different machining processes. More particles fell off the edge and more edge notches occurred in GM due to the dissolving of the metal matrix, as shown in Figure $9 \mathrm{~b}$. A higher proportion of plastic zones made the edge relatively flat with ZUE/DM. The edge notches were filled with the metal matrix in XUE/DM and 2UE/DM after the exposed broken ceramic particles were dragged and crushed. However, the latter had fewer notched and neat edges. These topographic characteristics verified the removal mechanism of MMCs in 2UE/DM and its efficacy. As shown in Figure 10, the precision of the edge produced by 2UE/DM was the lowest (only about $6.8 \%$ ) and slightly lower than that produced by ZUE/DM and XUE/DM; however, it produced reductions of about $24 \%$ and $47 \%$ compared to GE/DM and GM, respectively. The results indicated that the twodimensional ultrasonic vibration increased MRR while enhancing the machining quality. The machining performance of 2UE/DM was significantly better than that of the other four machining techniques: 2UE/DM is a high-speed, high-quality, and reliable technology for machining MMCs. 

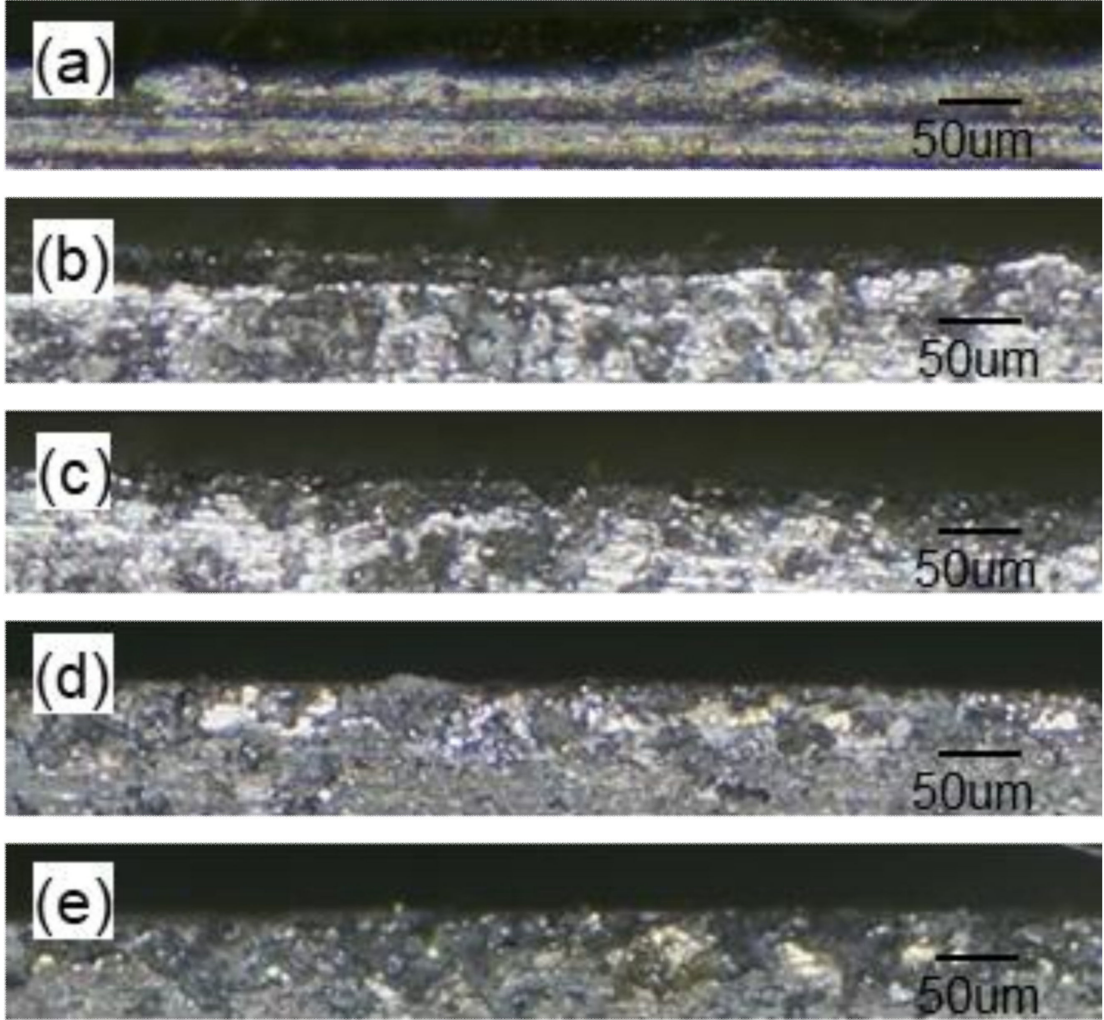

Figure 9. Comparison of edges: (a) GM; (b) GE/DM; (c) ZUE/DM; (d) XUE/DM; (e) 2UE/DM.

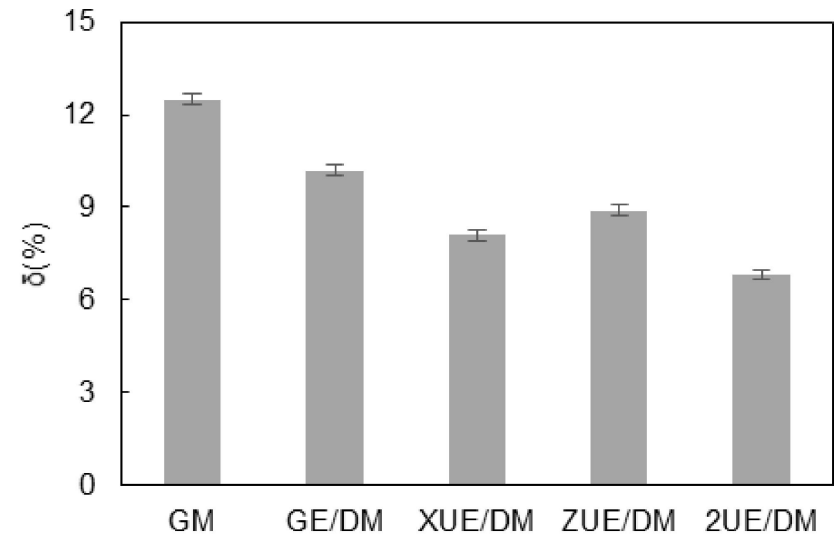

Figure 10. Comparison of form precision.

\section{Effects of Process Parameters on 2UE/DM}

\section{1. $M R R$}

Figure 11 shows the MRR of 2UE/DM of different process parameters. The MRR did not increase with an increase in the rotational speed, and MRR decreased rapidly at $5000 \mathrm{rpm}$. The gathered bubbles in the gap did not easily form a gas film under the action of centrifugal force, reducing the discharge frequency of DM and the dissolution rate of ECM. Voltage had a stronger impact on the MRR, while the MRR reached $0.89 \mathrm{~mm}^{3} / \mathrm{min}$ in $6 \mathrm{~V}$, indicating that, with an increase in voltage, the electrolysis/electro-discharge action between electrodes was intensified and the percent of volume removed by electrolysis/electrodischarge increased with an increase in voltage [26]. A $A_{X}$ had a significant impact on the MRR instead of $A_{Z}$. Grinding depth was greater and the volume of material removed by the grinding process was larger with an increasing $A_{X}$. The MRR at $5 \mu \mathrm{m}$ was 1.3 times that at $2 \mu \mathrm{m}$. The variation in the gap was beneficial for the formation of discharge channels, the cycles of electrolyte, optimization of the machining environment, and enhancement of 
the MRR. Therefore, to obtain a higher MRR for composites, lower rotational speed, higher voltage, and higher two-dimensional amplitude are recommended.

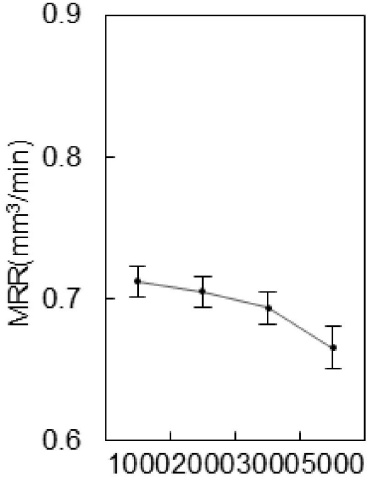

(a)n(rpm)

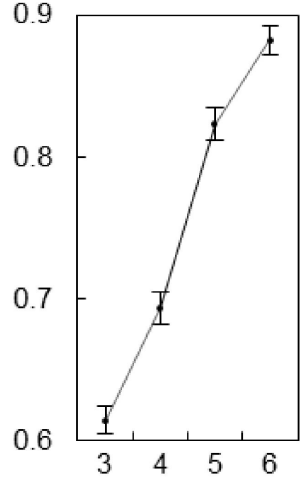

(b)U(V)

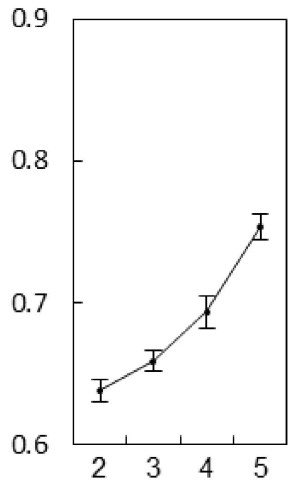

(c) $A_{x}($ um)

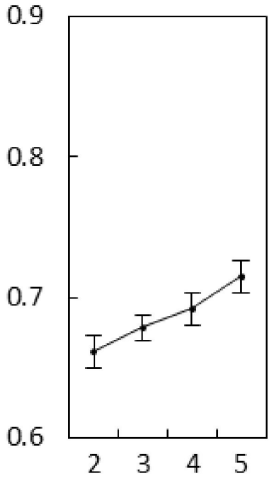

(d) $A_{z}$ (um)

Figure 11. Effects of machining parameters on MRR.

\subsection{Surface Quality}

The effects of 2UE/DM under different process parameters on surface roughness are shown in Figure 12. As the rotational speed increased, the number of particles that participate in grinding per unit time correspondingly increased and the surface roughness slightly decreased [28]. The depth and rate of the erosion on the metal matrix were greater with higher voltage, while more bubbles generated via electrolysis and electro-discharge between electrodes were more likely to occur and form pits. Then, reinforced particles were more likely to be exposed, resulting in a significant increase of Ra. The surface roughness at $6 \mathrm{~V}$ was found to be $1.4 \mu \mathrm{m}$ higher than at $3 \mathrm{~V}$. The abrasive particles increased the distance between the ridges as $\mathrm{A}_{Z}$ increased and reduced the residual height as $\mathrm{A}_{X}$ increased, resulting in lower $\mathrm{Ra}$. The $\mathrm{A}_{\mathrm{X}}$ was more advantageous than that of $\mathrm{A}_{Z}$ for improving surface quality. Electrical machining can reduce the actual chip depth of single grinding and accelerate material removal when the gap is small; in particular, it can reduce the residual height after cutting, thereby improving the surface quality after machining [29]. A reduction in cutting depth is beneficial for reducing surface damage. Therefore, to obtain a higher surface quality for a composite material, a lower speed and voltage and a larger two-dimensional ultrasonic amplitude are options to consider.



(a)n(rpm)

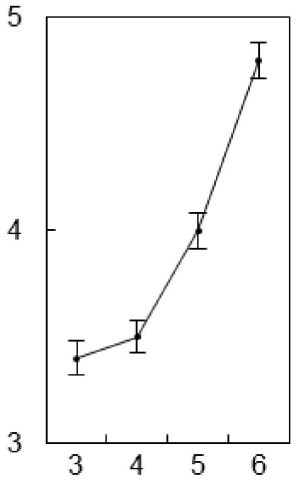

(b) U(V)

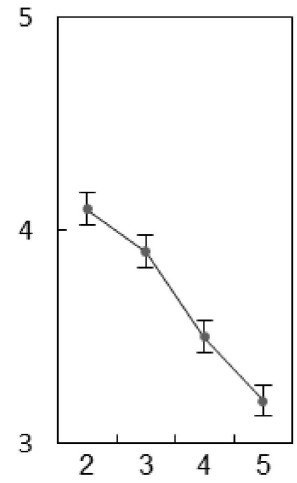

(c) $A_{X}$ (um)

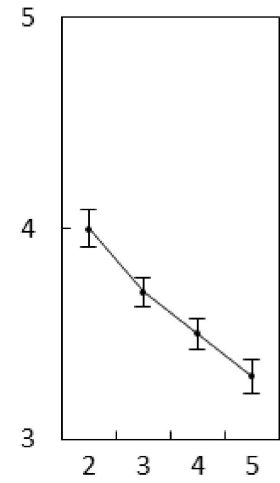

(d) $A_{z}$ (um)

Figure 12. Effects of machining parameters on Ra. 


\subsection{Form Precision}

Figure 13 shows the effects of different parameters on the edge precision in 2UE/DM. As seen, a higher rotational speed of the tool, greater than $3000 \mathrm{rpm}$, was more likely to cause more edge notches and decrease the form precision. When the applied voltage increased to $6 \mathrm{~V}, \delta$ increased accordingly because of the rapid dissolution of the metal matrix under a higher voltage. Additionally, the ceramic particles exposing and falling off under the action of abrasive particles led to poorer edge precision. Edge protrusions were more prone to inducing discharge with higher voltage, and then the cross-sectional area of the notch increased. The increase of $A_{X}$ and $A_{Z}$ facilitated the alternating action of abrasive particles on the edge, reducing the grinding force and simultaneously increasing the rolling-covered zone. When the amplitude was $5 \mu \mathrm{m}$, the form precision was reduced by about $27 \%$ and $21 \%$ compared to $2 \mu \mathrm{m}$. To obtain higher forming quality, a smaller applied voltage, an appropriate rotational speed, and a larger amplitude may be selected.

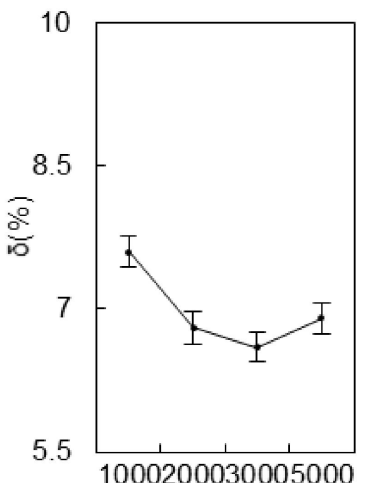

(a)n(rpm)

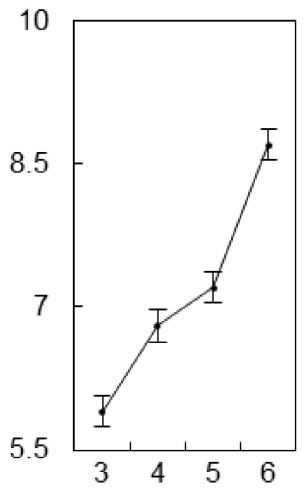

(b) U(V)

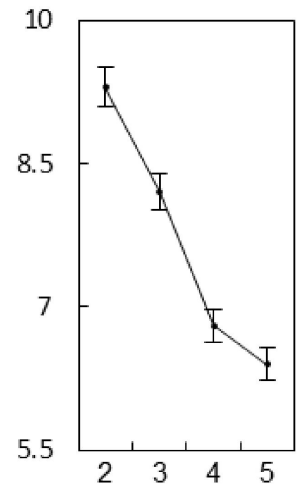

(c) $A_{X}(u m)$

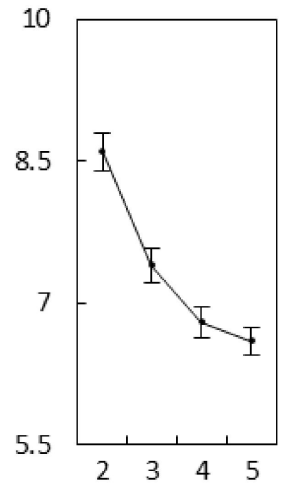

(d) $A_{z}(u m)$

Figure 13. Effects of machining parameters on $\delta$.

\subsection{Optimal Experiments}

In the single-factor tests in the previous section, the comprehensive influence of process parameters on machining performance could not be determined. Therefore, it was necessary to obtain the optimal process parameter design through orthogonal analysis. We considered spindle speed, voltage, and the vibration amplitude of the workpiece and tool as influential factors. Each factor had two levels (Table 4). A Taguchi test design $\left(\mathrm{L}_{8}\right)$ was established using Minitab software to optimize MRR, RA, and $\delta$ [30]. Table 5 shows that the maximum MRR occurred at $5000 \mathrm{rpm}, 6 \mathrm{~V}$, and $5 \mu \mathrm{m}$, whereas the minimum $\mathrm{Ra}$ and $\delta$ occurred at $1000 \mathrm{rpm}$ and $3 \mathrm{~V}$. The impact of different factors followed the sequence of $\mathrm{U}>\mathrm{A}_{X}>\mathrm{A}_{Z}>\mathrm{n}$. Table 6 shows that $\mathrm{U}$ and $\mathrm{A}_{X}$ always exhibited a positive effect on the MRR, $\mathrm{Ra}$, and $\delta$, whereas $\mathrm{A}_{\mathrm{Z}}$ and $\mathrm{n}$ had no significant impact on the MRR and $\delta$ individually. The result is reasonable since the vibration enhanced the EC/DM action and increased the cutting depth, reducing the height difference [31]. Verification experiments using the optimizing parameters $(1000 \mathrm{rpm}, 3 \mathrm{~V}$, and $5 \mu \mathrm{m})$ were conducted on $40 \mathrm{SiCp} / \mathrm{Al}$, and the MRR, Ra, and $\delta$ were $0.76 \mathrm{~mm}^{3} / \mathrm{min}, 3.35 \mu \mathrm{m}$, and $5.84 \%$, respectively. An enlarged view of the machined surface and edge is shown in Figures 13 and 14, which indicate that 2UEC/DM showed higher machining efficiency and forming quality in machining MMCs.

Table 4. Level of factors for 2UE/DM.

\begin{tabular}{ccccc}
\hline Levels & A:n $(\mathbf{r p m})$ & B:U (V) & C:Ax $(\mu \mathrm{m})$ & D:Az $(\mu \mathrm{m})$ \\
\hline $\mathbf{- 1}$ & 1000 & 3 & 2 & 2 \\
\hline $\mathbf{1}$ & 5000 & 6 & 5 & 5 \\
\hline
\end{tabular}


Table 5. Results of the orthogonal analysis.

\begin{tabular}{|c|c|c|c|c|c|c|c|}
\hline Run No. & A & B & C & D & $\begin{array}{c}\text { MRR } \\
\left(\mathrm{mm}^{3} / \mathrm{min}\right)\end{array}$ & $\operatorname{Ra}(\mu \mathrm{m})$ & $\delta(\%)$ \\
\hline 1 & -1 & -1 & -1 & -1 & 0.68 & 4.28 & 8.43 \\
\hline 2 & -1 & -1 & 1 & 1 & 0.77 & 3.43 & 5.96 \\
\hline 3 & -1 & 1 & -1 & 1 & 0.87 & 4.52 & 9.27 \\
\hline 4 & -1 & 1 & 1 & -1 & 0.90 & 4.35 & 8.82 \\
\hline 5 & 1 & -1 & -1 & 1 & 0.65 & 3.79 & 7.32 \\
\hline 6 & 1 & -1 & 1 & -1 & 0.72 & 3.60 & 7.23 \\
\hline 7 & 1 & 1 & -1 & -1 & 0.79 & 4.61 & 10.42 \\
\hline 8 & 1 & 1 & 1 & 1 & 0.91 & 3.78 & 8.21 \\
\hline
\end{tabular}

Table 6. ANOVA for MRR, Ra, and $\delta$.

\begin{tabular}{ccccccc}
\hline Source & $\mathbf{F}$ (MRR) & $\mathbf{P}(\mathbf{M R R})$ & $\mathbf{F ~ ( R a )}$ & $\mathbf{P}(\mathbf{R a})$ & $\mathbf{F}(\boldsymbol{\delta})$ & $\mathbf{P}(\boldsymbol{\delta})$ \\
\hline A & 21.43 & 0.036 & 9.83 & 0.004 & 0.02 & 0.197 \\
\hline B & 77.36 & 0.001 & 28.11 & 0.000 & 106.36 & 0.000 \\
\hline C & 17.36 & 0.005 & 44.49 & 0.000 & 12.19 & 0.001 \\
\hline D & 13.71 & 0.076 & 21.33 & 0.001 & 14.82 & 0.002 \\
\hline
\end{tabular}
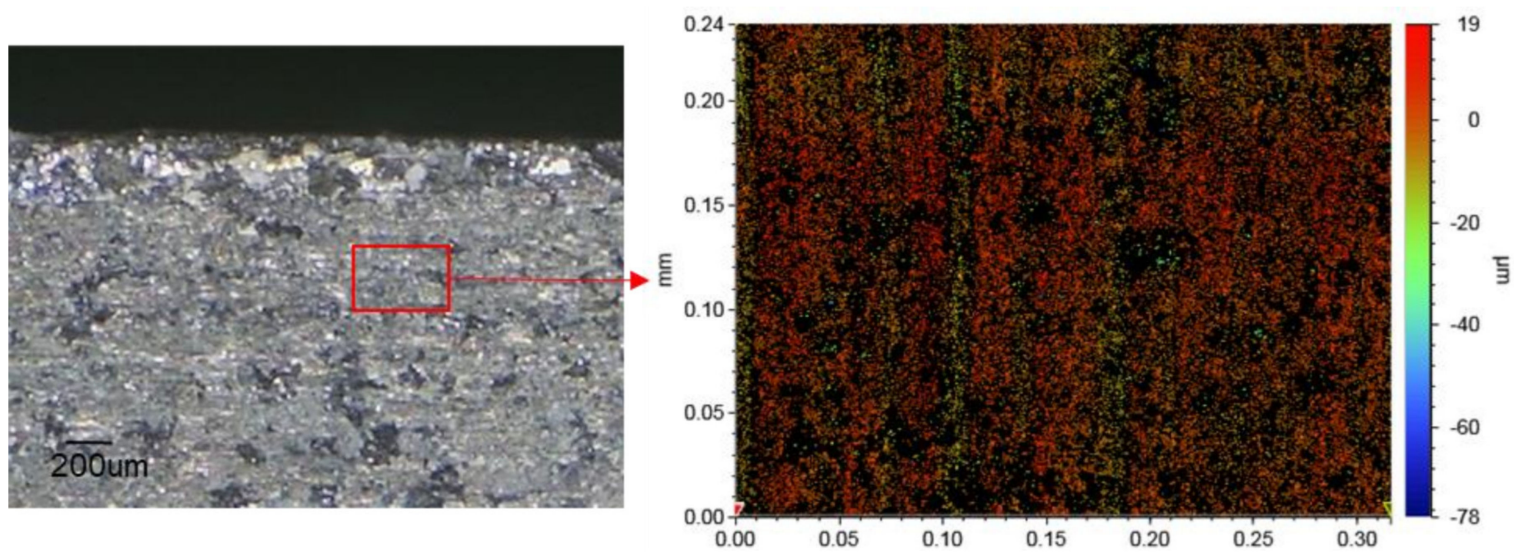

Figure 14. The machined surface and topography in optimized parameters.

\section{Conclusions}

In this research, the 2UE/DM method was developed for machining hard and brittle conductive materials of MMCs (40 SiCp/Al). Our experimental research focused on the MRR, Ra, and $\delta$ under different machining processes and parameters. According to the test results, we drew the following conclusions:

(1) Due to the addition of two-dimensional ultrasonic vibration, the removal mechanism of MMCs in generating machining of EC/DM changed. The 2UE/DM combined the advantages of $2 \mathrm{UM}, \mathrm{ECM}$, and DM, improving the machining efficiency and quality significantly.

(2) Despite the higher dissolution rate of the metal matrix in 2UEC/DM enlarging the height difference between ridges and craters, the two-dimensional ultrasonic vibration extended the abrasive cutting path and scraped off the exposed ceramic matrix particles and hard-to-dissolve bumps plastically, resulting in a lower surface roughness.

(3) The machining performance correspondingly increased with higher process parameters except for the spindle speed, which easily caused edge chipping of the machined 
surface and increased the form precision. The $\mathrm{Z}$ amplitude had no significant impact on the MRR. All the selected parameters of the $X$ amplitude and applied voltage had a considerable impact on the MRR, surface quality, and form precision.

(4) The optimized process parameters for $40 \mathrm{SiCp} / \mathrm{Al}$ included a spindle speed of 1000 $\mathrm{rpm}$, a voltage of $3 \mathrm{~V}$, and two amplitudes of $5 \mu \mathrm{m}$, achieving a maximum MRR of $0.76 \mathrm{~mm} 3 / \mathrm{min}$ and minimum Ra and $\delta$ values of $3.35 \mu \mathrm{m}$ and $5.84 \%$, respectively.

Author Contributions: Funding acquisition, Y.Z.; supervision, Y.Z.; validation, J.L. and W.C.; writing —original draft, J.L.; writing—review and editing, J.L. and Y.Z. All authors have read and agreed to the published version of the manuscript.

Funding: This research was funded by the National Natural Science Foundation of China (51775484 and 52175438) and the 2021 Jiangsu Province Postgraduate Highlights Study Project.

Institutional Review Board Statement: Not applicable.

Informed Consent Statement: Not applicable.

Data Availability Statement: Data is contained within the article.

Conflicts of Interest: The authors declare no conflict of interest.

\section{Nomenclature}

UE/DM Ultrasonic vibration-composited electrolysis/electro-discharge machining

2UE/DM Two-dimensional ultrasonic vibration-composited electrolysis/

electro-discharge machining

2UM Two-dimensional ultrasonic vibration assisted grinding machining

ECM Electrolysis machining

EDM Electro-discharge machining

DM Discharge machining

GM Grinding machining

ECDM Electrolytic discharge machining

E/DM Electrolytic/electro-discharge machining

GE/DM Grinding composited electrolysis/electro-discharge machining

ZUE/DM Grinding composited electrolysis/electro-discharge machining with $Z$ vibration

XUE/DM Grinding composited electrolysis/electro-discharge machining with $X$ vibration

MMC Metal matrix composites

$\mathrm{Ra} \quad$ Surface roughness

$\delta \quad$ Form precision

$\mathrm{A}_{\mathrm{Z}} \quad$ Vibration amplitude of Z-direction

$\mathrm{f}_{\mathrm{Z}} \quad$ Vibration frequency of $Z$-direction

$\mathrm{A}_{\mathrm{X}} \quad$ Vibration amplitude of $X$-direction

$\mathrm{f}_{\mathrm{X}} \quad$ Vibration frequency of $\mathrm{X}$-direction

n Spindle speed

$\mathrm{G}(t) \quad$ Machining gap

$i \quad$ Current density

$\mathrm{U}_{\mathrm{R}} \quad$ Applied voltage drop

$\mathrm{S}_{\mathrm{b}} \quad$ Cross-sectional area

$\mathrm{S}_{\mathrm{c}} \quad$ Theoretical cross-sectional area

$\mathrm{S} \quad$ Machining surface area of workpiece

I Current

L Length the measured area

$\mathrm{H}$ Depth of the largest notch

MRR Material remove rate 


\section{References}

1. Kumar, P.; Jadhav, P.; Beldar, M.; Jadhav, D.B.; Sawant, A. Review Paper on ECM, PECM and Ultrasonic Assisted PECM. Mater. Today Proc. 2018, 5 Pt 1, 6381-6390. [CrossRef]

2. Wang, J.; Zhang, J.; Feng, P.; Guo, P. Experimental and theoretical investigation on critical cutting force in rotary ultrasonic drilling of brittle materials and composites. Int. J. Mech. Sci. 2018, 135, 555-564. [CrossRef]

3. Bertsche, E.; Bertsche, E.; Ehmann, K.; Ehmann, K.; Malukhin, K.; Malukhin, K. Ultrasonic slot machining of a silicon carbide matrix composite. Int. J. Adv. Manuf. Technol. 2013, 66, 1119-1134. [CrossRef]

4. Ghoshal, B.; Bhattacharyya, B. Vibration assisted electrochemical micromachining of high aspect ratio micro features. Precis. Eng. 2015, 42, 231-241. [CrossRef]

5. Ning, F.; Wang, H.; Cong, W.; Fernando, P.K.S.C. A mechanistic ultrasonic vibration amplitude model during rotary ultrasonic machining of CFRP composites. Ultrasonics 2017, 76, 44-51. [CrossRef] [PubMed]

6. Liu, J.W.; Yue, T.M.; Guo, Z.N. An analysis of the discharge mechanism in electrochemical discharge machining of particulate reinforced metal matrix composites. Int. J. Mach. Tools Manuf. 2010, 50, 86-96. [CrossRef]

7. Müller, F.; Monaghan, J. Non-conventional machining of particle reinforced metal matrix composite. Int. J. Mach. Tools Manuf. 2000, 40, 1351-1366. [CrossRef]

8. Elhami, S.; Razfar, M.R. Application of nano electrolyte in the electrochemical discharge machining process. Precis. Eng. 2020, 64, 34-44. [CrossRef]

9. Singh, M.; Singh, S. Electrochemical discharge machining: A review on preceding and perspective research. Proc. Inst. Mech. Eng. Part B J. Eng. Manuf. 2017, 233, 1425-1449. [CrossRef]

10. Liu, J.W.; Yue, T.M.; Guo, Z.N. Grinding-aided electrochemical discharge machining of particulate reinforced metal matrix composites. Int. J. Adv. Manuf. Technol. 2013, 68, 2349-2357. [CrossRef]

11. Kanagarajan, D.; Palanikumar, K.; Karthikeyan, R. Effect of Electrical Discharge Machining on strength and reliability of WC-30\%Co composite. Mater. Des. 2012, 39, 469-474. [CrossRef]

12. Nani, V. Ultrasound influence on the erosive capacity at the electrodischarge processing with ultrasonic activated wire electrode in a single point. Meccanica 2017, 52, 1459-1474. [CrossRef]

13. El-Hofy, H. Vibration-assisted electrochemical machining: A review. Int. J. Adv. Manuf. Technol. 2019, 105, 579-593. [CrossRef]

14. Anasane, S.S.; Bhattacharyya, B. Experimental investigation into micromilling of microgrooves on titanium by electrochemical micromachining. J. Manuf. Process. 2017, 28, 285-294. [CrossRef]

15. Ghoshal, B.; Bhattacharyya, B. Influence of vibration on micro-tool fabrication by electrochemical machining. Int. J. Mach. Tools Manuf. 2013, 64, 49-59. [CrossRef]

16. Pawariya, K.; Dvivedi, A.; Singh, T. On performance enhancement of electrochemical discharge trepanning (ECDT) process by sonication of tool electrode. Precis. Eng. 2019, 56, 8-19. [CrossRef]

17. Wang, M.; Chen, X.; Tong, W.; Wang, J.; Wang, X. Influences of gap pressure on machining performance in radial ultrasonic rolling electrochemical micromachining. Int. J. Adv. Manuf. Technol. 2020, 107, 157-166. [CrossRef]

18. Kumar, R.; Singh, A.; Singh, I. Electric discharge hole grinding in hybrid metal matrix composite. Mater. Manuf. Processes 2017, 32, 127-134. [CrossRef]

19. Elhami, S.; Razfar, M.R. Study of the current signal and material removal during ultrasonic-assisted electrochemical discharge machining. Int. J. Adv. Manuf. Technol. 2017, 92, 1591-1599. [CrossRef]

20. Elhami, S.; Razfar, M.R. Analytical and experimental study on the integration of ultrasonically vibrated tool into the micro electro-chemical discharge drilling. Precis. Eng. 2017, 47, 424-433. [CrossRef]

21. Kolhekar, K.R.; Sundaram, M. Study of gas film characterization and its effect in electrochemical discharge machining. Precis. Eng. 2018, 53, 203-211. [CrossRef]

22. Schubert, A.; Zeidler, H.; Oschätzchen, M.H.; Schneider, J.; Hahn, M. Enhancing Micro-EDM using Ultrasonic Vibration and Approaches for Machining of Nonconducting Ceramics. Stroj. Vestn. J. Mech. Eng. 2013, 59, 156-164. [CrossRef]

23. Zhu, G.; Zhang, M.; Zhang, Q.; Song, Z.; Wang, K. Machining behaviors of vibration-assisted electrical arc machining of $\mathrm{W}_{9} \mathrm{Mo}_{3} \mathrm{Cr}_{4}$ V. Int. J. Adv. Manuf. Technol. 2018, 96, 1073-1080. [CrossRef]

24. Zhang, Y.; Xu, Z.; Zhu, D.; Xing, J. Tube electrode high-speed electrochemical discharge drilling using low-conductivity salt solution. Int. J. Mach. Tools Manuf. 2015, 92, 10-18. [CrossRef]

25. Ge, Y.; Zhu, Z.; Wang, D.; Ma, Z.; Zhu, D. Study on material removal mechanism of electrochemical deep grinding. J. Mater. Process. Technol. 2019, 271, 510-519. [CrossRef]

26. Wang, H.; Zhang, D.; Li, Y.; Cong, W. The effects of elliptical ultrasonic vibration in surface machining of CFRP composites using rotary ultrasonic machining. Int. J. Adv. Manuf. Technol. 2020, 106, 5527-5538. [CrossRef]

27. Sreehari, D.; Sharma, A.K. On form accuracy and surface roughness in micro-ultrasonic machining of silicon microchannels. Precis. Eng. 2018, 53, 300-309. [CrossRef]

28. Thiagarajan, C.; Sivaramakrishnan, R.; Somasundaram, S. Experimental evaluation of grinding forces and surface finish in cylindrical grinding of $\mathrm{Al} / \mathrm{SiC}$ metal matrix composites. Proc. Inst. Mech. Eng. Part B J. Eng. Manuf. 2011, 225, 1606-1614. [CrossRef] 
29. Hu, Y.; Shi, D.; Hu, Y.; Zhao, H.; Sun, X. Investigation on the Material Removal and Surface Generation of a Single Crystal SiC Wafer by Ultrasonic Chemical Mechanical Polishing Combined with Ultrasonic Lapping. Materials 2018, 11, 2022. [CrossRef] [PubMed]

30. Phan, N.H.; Muthuramalingam, T. Multi Criteria Decision Making of Vibration Assisted EDM Process Parameters on Machining Silicon Steel Using Taguchi-DEAR Methodology. Silicon 2020, 13, 1879-1885. [CrossRef]

31. Ge, Y.; Zhu, Z.; Wang, D. Electrochemical Dissolution Behavior of the Nickel-Based Cast Superalloy $\mathrm{K}_{42} 2 \mathrm{~A}$ in $\mathrm{NaNO}_{3}$ Solution. Electrochim. Acta 2017, 253, 379-389. [CrossRef] 